\title{
Effects of constantly high soil water content on vegetative growth and grape quality in Japan with high rainfall during grapevine growing season
}

\author{
Yuta Kobayashil,2, Tetsunan Yamamoto', Hironori Ikeda ${ }^{3}$, Ryuzo Sugihara ${ }^{3}$, \\ Hiroki Kaihori ${ }^{3}$, Masahiro Kawabata ${ }^{3}$, Shunji Suzuki, *
}

${ }^{1}$ Laboratory of Fruit Genetic Engineering, Institute of Enology and Viticulture, University of Yamanashi, Kofu, Yamanashi 400-0005, Japan ${ }^{2}$ Experimental Farm, Faculty of Life and Environmental Sciences, University of Yamanashi, Kofu, Yamanashi 400-0841, Japan ${ }^{3}$ Industrial Solutions Company, Business Development Center, Energy Business Development Sector, Panasonic Corporation, 1-1 Matsushita-cho, Moriguchi, Osaka 570-8511, Japan

\begin{abstract}
Excess water in vineyard soils during grapevine growing season is expected to become a critical issue in Japan. The objective of this study was to investigate the effects of constantly high soil water content which was controlled at constantly more than $20 \%$ water content in soil on vegetative growth and berry quality of Cabernet Sauvignon over a 3-year growing season. A wireless sensor networking system for real-time monitoring of soil moisture was used to check that the experimental plot had constantly more than $20 \%$ water content in soil. Véraison in the experimental plot controlled at constantly high soil water content started 10 days, 4 days and 1 day later than that in the non-irrigated experimental plot in the 2017, 2018 and 2019 growing seasons, respectively. The constantly high soil water content had no notable effects on berry quality, such as berry characteristics and berry composition, at harvest compared with the non-irrigated experimental plot, although there was a certain tendency that constantly high soil water content decreased anthocyanin contents in berry skins compared with those of non-irrigated grapevines during the three growing seasons. We postulated that waterlogging damage due to the increase in soil water content by frequent rainfall would be minimised by the selection of rootstock that confers tolerance to waterlogging stress for scion cultivars and/or viticultural practices to prevent decrease in soil temperature. Also, the introduction of Internet of Things technology for monitoring water status in vineyard soil is expected to contribute to improving practical approaches to vineyard soil water management.
\end{abstract}

Keywords: Cabernet Sauvignon, soil water content, Vitis vinifera, waterlogging damage, wireless sensor networking system

\section{INTRODUCTION}

Soil water content markedly affects grapevine growth, yield and quality (Bravdo et al., 1985). Global warming, which has accelerated in major wine-producing countries, has caused soil drying in vineyards. A simulation model has predicted an average temperature increase of $2^{\circ} \mathrm{C}$ in viticulture regions in the next 50 years (Jones et al.,
2005). One of the countermeasures for loss of soil water content is irrigation. Although non-irrigated grapevines have been traditionally cultivated in Mediterraneantype climates (Schultz, 2003), viticultural irrigation is required in response to global warming, for example, in Portugal (Fraga et al., 2018). 
The climate change scenario has also increased the amount of precipitation. Global warming has led to moistening of the atmosphere and an intensification of the hydrologic cycle (Frei et al., 1998). For example, heavy rainfall was recorded over wide areas in Japan from June 28 to July 8 in 2018 . The heavy rainfall event was responsible for the prolonged concentration of extremely moist airstreams over Japan (Tsuguti et al., 2019). Climate simulation models have demonstrated an elevated risk of heavy rainfall in early summer (MayJuly) in Japan (Yokoyama et al., 2019). Another climate simulation model has also indicated that monthly precipitation in Japan during summer (June-August) will increase as temperature increases over wide areas of Japan (Hatsuzuka and Sato, 2019). Thus, at least in Japan, an excess of water in vineyard soils during grapevine growing season is expected to become a critical issue.

The objective of this study was to investigate the effects of constantly high soil water content on vegetative growth and berry quality of Cabernet Sauvignon. Over a 3-year growing season, we examined the effects of constantly high soil water content which was controlled at constantly more than $20 \%$ using a wireless sensor networking system for real-time monitoring of soil water content and an irrigation system on vegetative growth and berry quality of Cabernet Sauvignon cultivated in Yamanashi Prefecture, the largest wine-producing region in Japan. To understand the threshold for optimum irrigation, measurement of soil water content was performed using a wireless sensor networking system. Soil moisture sensors have been developed to improve measurement accuracy (Gao et al., 2018) as well as to reduce introduction cost (González-Teruel et al., 2019). A wireless sensor networking system has been developed for real-time monitoring of soil water content (Nooriman et al., 2018). Uninterrupted real-time monitoring of grapevine growth environment including soil water content is expected for precision viticulture in the near future (Spachos and Gregori, 2019).

\section{MATERIALS AND METHODS}

\section{Cultivation area}

Vitis vinifera cv. Cabernet Sauvignon was cultivated in the Experimental Farm of the Faculty of Life and Environmental Sciences, University of Yamanashi, Japan (latitude, $35^{\circ} 36^{\prime} 14.0688^{\prime \prime} \mathrm{N}$; longitude, $138^{\circ} 34^{\prime}$ 41.9016" E; elevation, $250 \mathrm{~m}$ ). The farm was located on flat land and had conventional under-drainage pipes. Soils had sandy loam texture with the following characteristics: clay $5.0 \%$, silt $19.0 \%$, sand $76.0 \%, \mathrm{pH}$ $6.4, \mathrm{EC}=16.0 \mu \mathrm{S} \cdot \mathrm{cm}^{-1}$, bulk density $1.12 \pm 0.03 \mathrm{~g} \cdot \mathrm{cc}^{-1}$.

\section{Plant material}

Nine-year-old grapevines were trained to a cordon using 101-14 Millardet et de Grasset rootstock. Each vine was planted $2 \mathrm{~m}$ apart with $2-\mathrm{m}$ row spacing. Inter-row was covered with mown grass sward. Fruit-zone leaf removal was performed in mid-June. The average yield was adjusted to two bunches per shoot and the crop yield was adjusted to approximately $15,000 \mathrm{~kg} \cdot \mathrm{ha}^{-1}$. Pesticide and fungicide applications were performed 9 and 10 times, respectively, from April to November in each year.

\section{Weather data}

Weather data were recorded by a Meteorological Observation System (FieldMini-FMC-WJ-01, FieldPro, Tokyo, Japan) located approximately $50 \mathrm{~m}$ from the grapevines tested. Average temperatures, maximum and minimum temperatures and precipitation from April 1 through October 31 were summarised monthly for each growing season. Growing degree days (GDD, base threshold of $10^{\circ} \mathrm{C}$ ) from April 1 through October 31 were calculated monthly for each growing season.

\section{Real-time monitoring of soil water content using a wireless sensor networking system}

Two experimental plots each measuring $20 \mathrm{~m} \times 4 \mathrm{~m}$ were prepared and 10 grapevines were cultivated in each plot. Three soil moisture and temperature sensors were set in each plot. The sensors (5TE soil moisture sensor, Decagon Devices, Inc., Pullman, WA) were buried underground (20 cm depth) at the distance of $30 \mathrm{~cm}$ from a grapevine trunk on 14 March 2017 (Figure 1). The sensors were set $5 \mathrm{~m}$ apart between sensors and numbered, as shown in Figure 2. The sensors were connected to sensor nodes by cables (Figure 2). Soil volumetric water content, soil temperature and electric conductivity measured by the sensors were transmitted every $10 \mathrm{~min}$ from each sensor node to a Gateway computer through an in-field local wireless network. The data were transmitted to a cloud server on the internet through a cellular communication network. Soil water content (\%) was expressed as volumetric water content $(\theta)$. The sensors were regularly calibrated according to the manufacturer's instructions during the experimental period.

\section{Irrigation system for constantly high soil water content}

A drip irrigation tube (polyethylene irrigation tube, $0.20 \mathrm{~mm}$ thick, $0.6 \mathrm{~mm}$ pore diameter, $20 \mathrm{~cm}$ spacing between pores; Kami Plus Co., Tokyo, Japan) was set on the ground near each grapevine trunk in one of the two experimental plots (Figure 1). Four sheets were spread to cover the experimental plot in which the irrigation tube was set to prevent water evaporation from soil and to maintain soil moisture (Figure 1). The sheets used in this study were as follows: polyethylene film (agricultural polyethylene film 95, $0.03 \mathrm{~mm}$ thick, $95 \mathrm{~cm}$ wide; Sumikasekisui Film Co., Ltd., Tokyo, Japan), ground sheet (Dio ground sheet, $0.5 \mathrm{~mm}$ thick, $200 \mathrm{~cm}$ wide; Dio Chemicals Ltd., Tokyo, Japan), mulch sheet (Agricultural mulch sheet hard type, $0.02 \mathrm{~mm}$ 
A

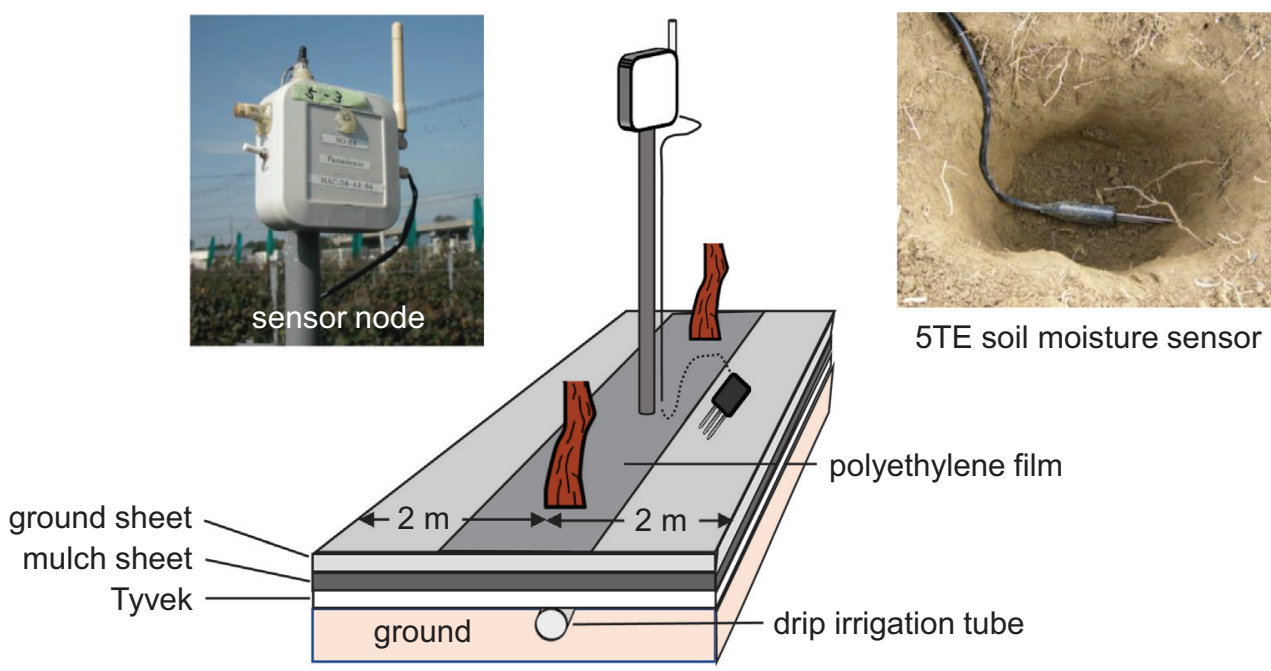

B

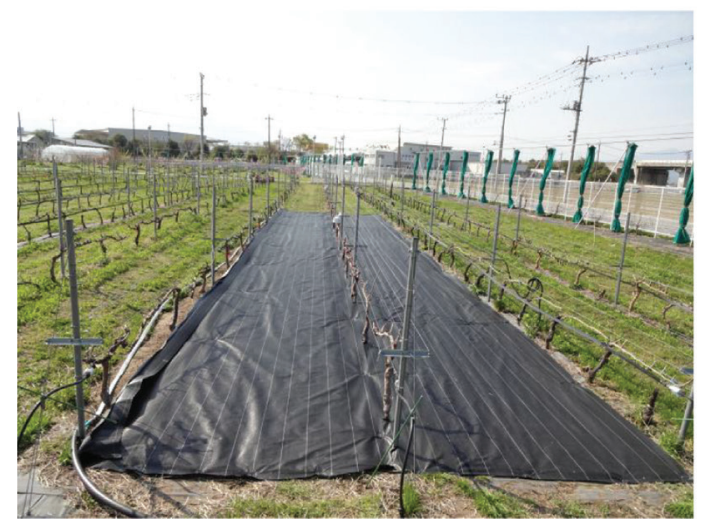

C
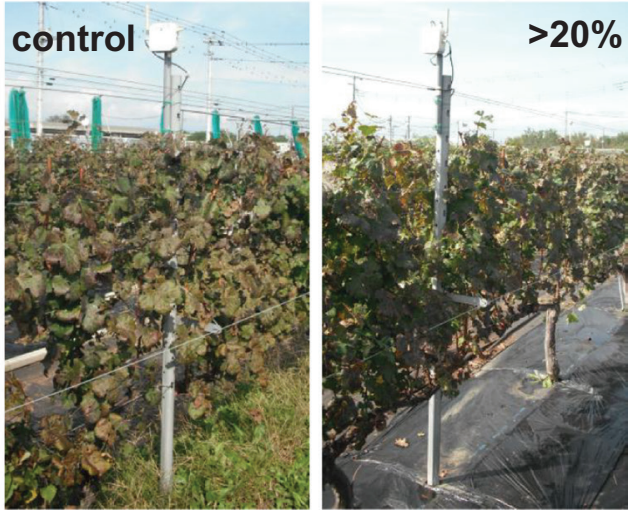

Figure 1. Deployment of a wireless sensor networking system for real-time monitoring of soil water content and an irrigation system. (A) Schematic representation of an experimental plot whose soil water content was controlled to more than 20\% using an irrigation system and sheet treatment. (B) Photograph of an experimental plot $(20 \mathrm{~m} \times 4 \mathrm{~m})$ whose soil water content was controlled to more than $20 \%$. Ten grapevines were cultivated in the plot. (C) Photographs of grapevines in the experimental plots. Control, non-irrigated grapevines; $>20 \%$, irrigated grapevines.

thick, $200 \mathrm{~cm}$ wide; Okura Industrial Co., Ltd.) and Tyvek (house wrap hard type, $0.17 \mathrm{~mm}$ thick, $200 \mathrm{~cm}$ wide, DuPont, Wilmington, DE). In the preliminary experiment, we confirmed that $170 \mathrm{~L}$ water was required to equalise the soil water contents with the $\mathrm{FC}$ value $(30-35 \%)$ in the irrigated experimental plot. Therefore, the experimental plot with the irrigation tube and sheets was irrigated with $170 \mathrm{~L}$ water for $10 \mathrm{~min}$ at 16:00 when soil water content in the experimental plot was less than $20 \%$.

\section{Vegetative growth characteristics}

The timings of bud break, bloom, full bloom, véraison and harvest were recorded in the three growing seasons. Harvest timing was decided according to a sugar-acid ratio. Since Cabernet Sauvignon used in the present study was cultivated under extremely high temperature in the farm with much rainfall (Table 1), berries at harvest tended to have low sugar content and high total acidity. Accordingly, harvest was performed at the day over sugar-acid ratio of $15: 1$. Since a sugar-acid ratio in 2017 growing season was not above 15:1 on in October (13:1), harvest was performed on October 4.

\section{Leaf water potential}

Leaf water potential was measured before and after véraison using a pressure chamber (Model 600D, PMS Instrument Company, Albany, OR). Briefly, three fully developed and undamaged leaves close to bunches were randomly selected. One leaf was placed in an SWP plant sample pack (grape pack, $15 \mathrm{~cm} \times 16.5 \mathrm{~cm}$; Meiwa Fosis, Tokyo, Japan). After shading the leaves in the packs for $1 \mathrm{~h}$, leaf water potential was measured in accordance with the manufacturer's instructions. Measurement of leaf water potential was performed at midday.

\section{Berry characteristics}

Berry characteristics were measured according to a previously described method (Kobayashi et al., 2020). Briefly, three bunches were randomly collected from 


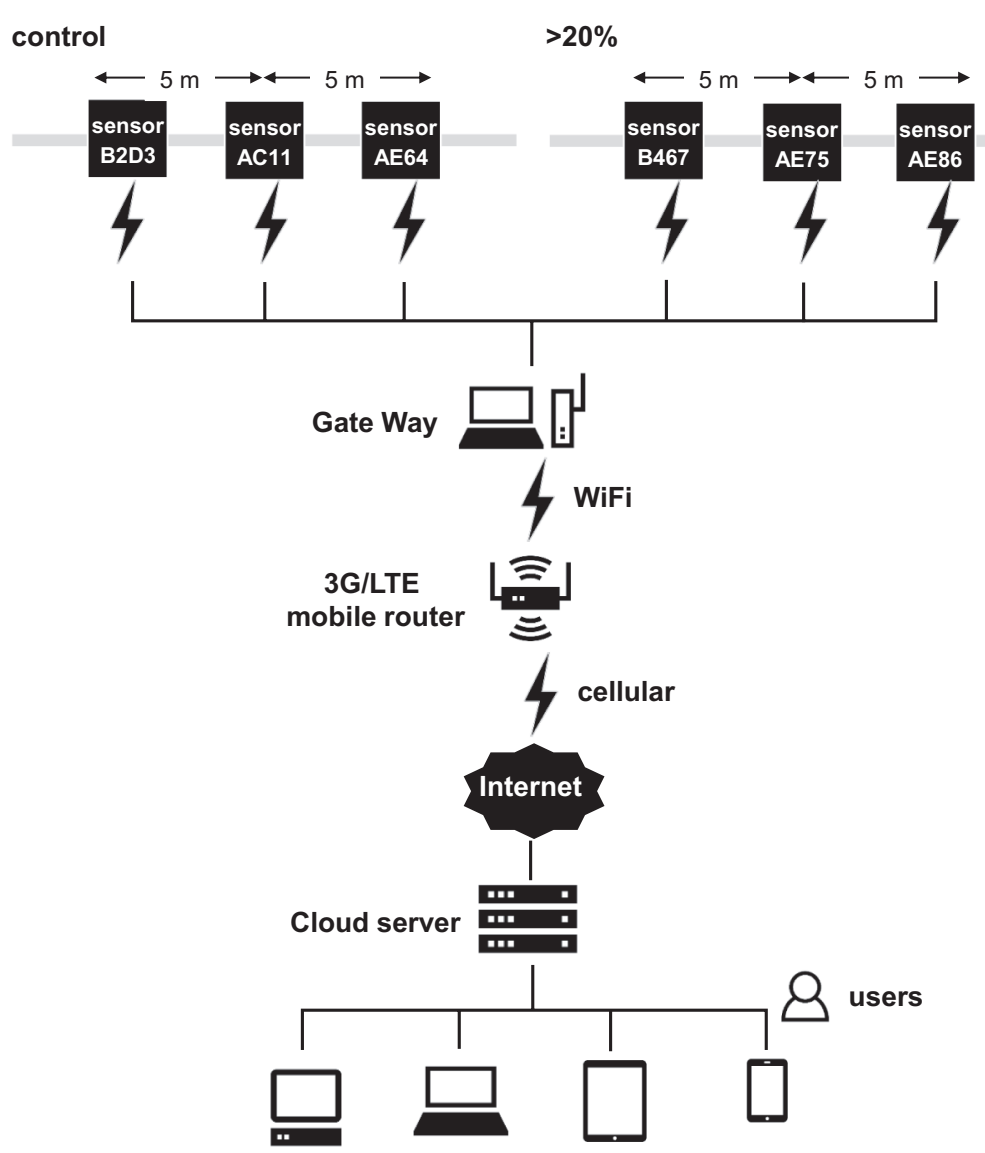

Figure 2. Schematic of a wireless sensor networking system developed for real-time monitoring of soil water content. Control, non-irrigated experimental plot and $>20 \%$, irrigated experimental plot with soil water content controlled to more than $20 \%$.

Table 1. Average temperatures, maximum and minimum temperatures, GDD and precipitation from April 1 to October 31 in the experimental farm

\begin{tabular}{|c|c|c|c|c|c|c|c|c|c|c|c|c|c|c|c|}
\hline \multirow[t]{2}{*}{ Month } & \multicolumn{3}{|c|}{$\begin{array}{l}\text { Average temperature } \\
\qquad\left({ }^{\circ} \mathrm{C}\right)\end{array}$} & \multicolumn{3}{|c|}{$\begin{array}{c}\text { Maximum } \\
\text { temperature }\left({ }^{\circ} \mathrm{C}\right)\end{array}$} & \multicolumn{3}{|c|}{$\begin{array}{c}\text { Minimum } \\
\text { temperature }\left({ }^{\circ} \mathrm{C}\right)\end{array}$} & \multicolumn{3}{|c|}{$\mathrm{GDD}^{\mathrm{a}}$} & \multicolumn{3}{|c|}{ Precipitation $(\mathrm{mm})$} \\
\hline & 2017 & 2018 & 2019 & 2017 & 2018 & 2019 & 2017 & 2018 & 2019 & 2017 & 2018 & 2019 & 2017 & 2018 & 2019 \\
\hline April & 13.2 & 15.6 & 13.2 & 21.0 & 23.9 & 20.8 & 6.8 & 8.5 & 5.9 & 96 & 169 & 96 & 85 & 76 & 52.5 \\
\hline May & 19.4 & 19.0 & 18.9 & 27.5 & 26.7 & 27.3 & 12.4 & 12.6 & 11.2 & 287 & 279 & 272 & 50.5 & 104.5 & 77.5 \\
\hline June & 21.9 & 22.4 & 21.9 & 29.5 & 29.0 & 28.6 & 15.8 & 16.9 & 16.8 & 356 & 372 & & & 68 & 133 \\
\hline July & 27.3 & 28.1 & 24.7 & 34.6 & 34.9 & 31.1 & 22.1 & 22.8 & 21.0 & 532 & 560 & 455 & 65.5 & 138.5 & 172.5 \\
\hline August & 27.2 & 27.7 & 27.6 & 34.3 & 35.3 & 34.9 & 22.6 & 22.2 & 23.1 & 534 & 550 & 546 & 129.5 & 134 & 111 \\
\hline September & 22.3 & 22.4 & 24.7 & 29.0 & 28.3 & 32.1 & 17.2 & 18.7 & 19.5 & 370 & 373 & 441 & 112.5 & 276 & 84.5 \\
\hline October & 16.2 & 17.6 & 18.3 & 21.3 & 25.0 & 23.9 & 12.0 & 12.0 & 14.2 & 194 & 238 & 264 & 455 & 41.5 & 306.5 \\
\hline Total & & & & & & & & & & 2369 & 2541 & 2432 & 952 & 838.5 & 937.5 \\
\hline
\end{tabular}

${ }^{\mathrm{a}} \mathrm{GDD}$, growing degree days; base threshold of $10^{\circ} \mathrm{C}$.

irrigated or non-irrigated grapevines every week from véraison (July 26) to harvest (October 4) in the 2017 growing season. Ten berries (three from the top of the bunch, four from the middle of the bunch and three from the bottom of the bunch) were collected from each bunch. The transverse diameter of each berry was measured using a digital calliper (AD-5764A-100, A\&D Co., Tokyo, Japan). The weights of the 10 berries were measured using an electronic balance (EK2000i, A\&D Co.). Soluble solids content (Brix) and total acid content (g $\cdot 100 \mathrm{~mL}^{-1}$ ) in juices prepared by hand-pressing each bunch were measured with a refractometer (PALBX1ACID2, Atago, Tokyo, Japan).

Ten bunches were collected at harvest (4 October 2017, 1 October 2018 and 28 September 2019, respectively). The number of berries on each bunch 
was counted. The weights of each bunch and 10 berries (three from the top of the bunch, four from the middle of the bunch, and three from the bottom of the bunch) collected from each bunch were measured using the electronic balance. Bunch lengths and the transverse diameters of the 10 berries were measured using the digital calliper. Juices were prepared by hand-pressing each bunch. Soluble solids content (Brix) and total acid content $\left(\mathrm{g} \cdot 100 \mathrm{~mL}^{-1}\right)$ in juice were measured as described earlier. The measurement of total anthocyanins in berry skins was performed in accordance with a previously described method (Kobayashi et al., 2020). Anthocyanin content was calculated using a standard calibration curve and expressed as micrograms of malvidin 3-glucoside per $\mathrm{cm}^{2}$ of berry skin.

\section{Statistical analysis}

Data are expressed as means \pm standard errors of biological replicates and subjected to the Student's $t$-test using Excel Statistics Software 2012 (Social Survey Research Information, Tokyo, Japan).

\section{RESULTS}

\section{Weather data}

The experimental farm in this study belonged to Region V on the Winkler Index. The GDD from April 1 to October 31 in the three growing seasons of 2017 through 2019 demonstrated that Cabernet Sauvignon was cultivated under extremely high temperatures (Table 1). Average temperatures and maximum and minimum temperatures were not significantly different among the growing seasons. The climate at the experimental farm was distinctive in that there was much rainfall from April to October. Precipitation from July in each growing season mostly exceeded $100 \mathrm{~mm}$. Remarkably, the precipitation in October 2017, September 2018 and October 2019 exceeded 450, 250 and $300 \mathrm{~mm}$, respectively (Table 1).

\section{Real-time monitoring of soil water content using a wireless sensor networking system}

To monitor soil volumetric water content in real time, a wireless sensor networking system was built (Figures 1 and 2). The system detected the increase in soil water content due to rainfall in the experimental plots in real time (Figure 3A). The system was also capable of detecting irrigation water (Figure 3B); it immediately detected the increase in soil water content in the experimental plot that had soil water content controlled to more than $20 \%$, when the plot was irrigated for $10 \mathrm{~min}$ at 16:00. Soil water content peaked 10-20 min after irrigation and decreased to $30 \%$ with time. These results suggested that the system could perform realtime monitoring of soil water content in an experimental plot and that soil water content in the experimental plot could be controlled to more than $20 \%$ using an irrigation system.

\section{Soil water contents in experimental plots}

Profiles of soil water content in the experimental plots, which were collected from April 21 to October 31 in the 2017 growing season, are shown in Figure 4. Malfunction of the wireless sensor networking system, which was mostly due to dead batteries, rarely led to data loss from each sensor. In the 2017 growing season, short periods of data loss due to dead batteries in the sensor nodes were observed from 10:30 to $11: 20$ on May 26 and 11:50 to 12:40 on September 8 for B2D3; from 13:00 to 13:10 on August 30 and at 13:20 on September 29 for AC11; at 12:40 on September 29 for AE64; from 9:40 to 11:10 on May 26 for B467; from 10:20 to 10:30 on May 26 for AE75 and from 15:00 to 15:50 on April 21 and at 10:50 on May 26 for AE86. A long period of data loss occurred from 10:40 on October 14 to October 31 for AC11, and from 21:20 on August 21 to 12:40 on August 30 for AE86. Since the sensor nodes of AC11 and AE86 were malfunctioned, they were replaced with new sensor nodes. Malfunctions of the system also occurred in the 2018 and 2019 growing seasons with similar frequency to the 2017 growing season (data not shown).

The averages of soil temperatures (means \pm standard deviations) from April to October in the non-irrigated experimental plot were $22.3 \pm 3.7^{\circ} \mathrm{C}$ as detected by $\mathrm{B} 2 \mathrm{D} 3 ; 22.7 \pm 3.2^{\circ} \mathrm{C}$ by $\mathrm{AC} 11$ and $22.6 \pm 3.5^{\circ} \mathrm{C}$ by AE64 in the 2017 growing season; $21.1 \pm 4.0^{\circ} \mathrm{C}$ as detected by $\mathrm{B} 2 \mathrm{D} 3 ; 21.5 \pm 4.2^{\circ} \mathrm{C}$ by $\mathrm{AC} 11$ and $21.3 \pm 4.4^{\circ} \mathrm{C}$ by AE 64 in the 2018 growing season and $21.9 \pm 3.9^{\circ} \mathrm{C}$ as detected by $\mathrm{B} 2 \mathrm{D} 3 ; 22.0 \pm 4.4^{\circ} \mathrm{C}$ by $\mathrm{AC} 11$ and $21.4 \pm 3.5^{\circ} \mathrm{C}$ by AE64 in the 2019 growing season. In contrast, the averages of soil temperatures (means \pm standard deviations) from April to October in the irrigated experimental plot were $24.6 \pm 3.7^{\circ} \mathrm{C}$ as detected by B $467 ; 24.4 \pm 4.0^{\circ} \mathrm{C}$ by $\mathrm{AE} 75$ and $24.8 \pm 3.8^{\circ} \mathrm{C}$ by AE86 in the 2017 growing seasons; $21.3 \pm 4.2^{\circ} \mathrm{C}$ as detected by B $467 ; 21.4 \pm 4.1{ }^{\circ} \mathrm{C}$ by $\mathrm{AE} 75$ and $19.4 \pm 2.9^{\circ} \mathrm{C}$ by $\mathrm{AE} 86$ in the 2018 growing seasons and $23.4 \pm 4.4^{\circ} \mathrm{C}$ as detected by $\mathrm{B} 467$; $22.7 \pm 4.5^{\circ} \mathrm{C}$ by AE75 and $21.4 \pm 4.5^{\circ} \mathrm{C}$ by AE86 in the 2019 growing season. The results suggested that sheet treatment for controlling soil water content to more than $20 \%$ prevented the decline of soil temperature by irrigation water and that soil temperature in the irrigated experimental plot was comparable with that in the non-irrigated experimental plot in the three growing seasons.

Soil water content in the non-irrigated experimental plot was less than 20\% except after rainfall (Figure 4). The averages of soil water contents from April to October in the non-irrigated experimental plot were $18.9 \%$ as detected by B2D3; $15.4 \%$ by AC11 and $15.9 \%$ by AE64 in the 2017 growing season (Figure 4A). In this study, to prepare the experimental plot having constantly high soil water content, soil water content in the irrigated experimental plot was controlled at constantly more than $20 \%$ water content in soil by irrigation. Soil water content in the irrigated experimental plot was constantly controlled to more than 20\% (Figure 4B). The averages 
A

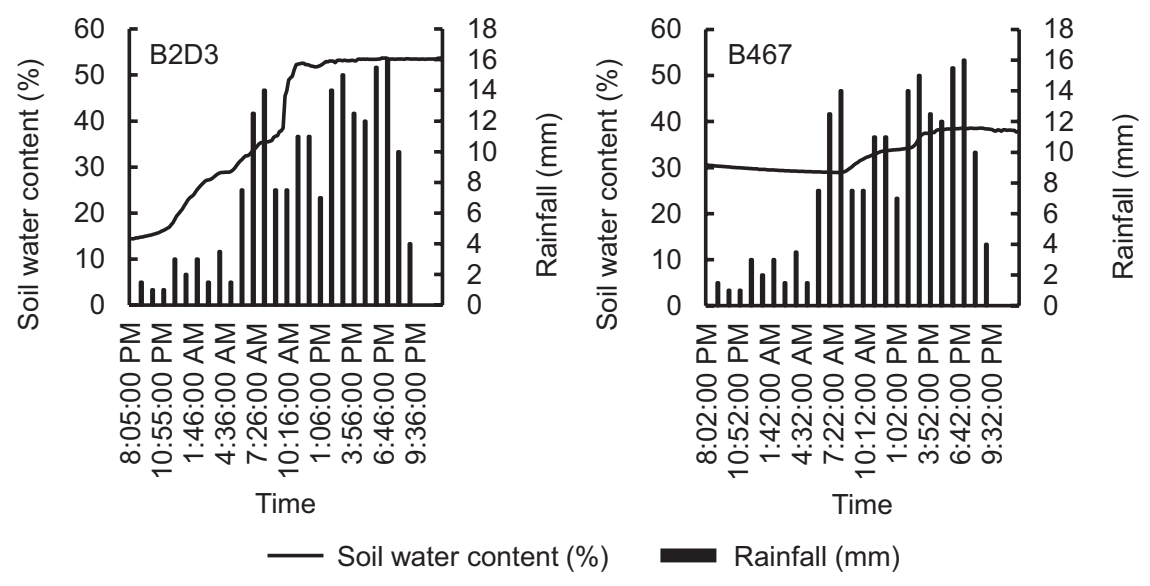

B
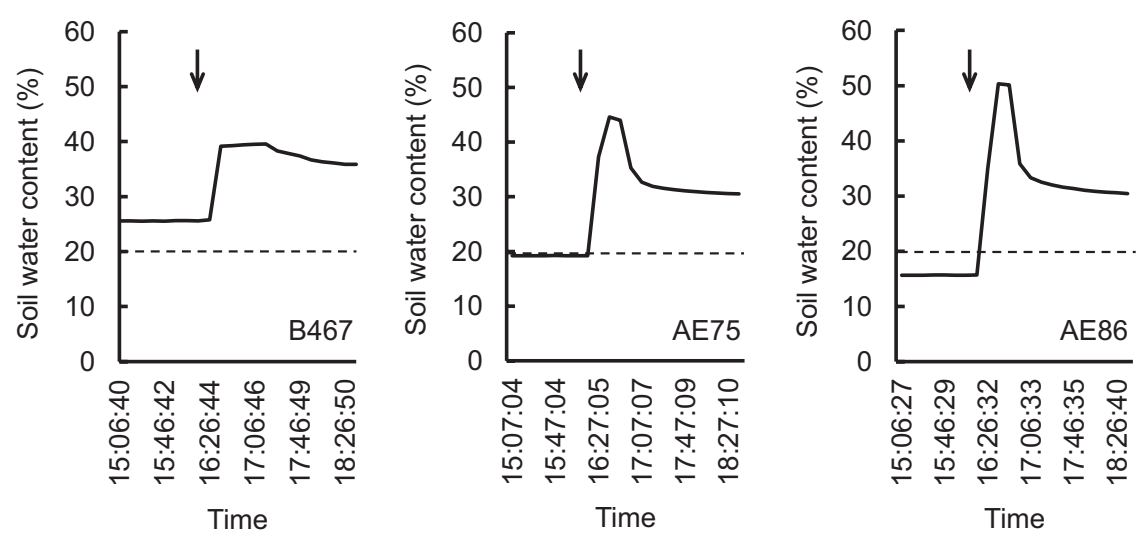

Figure 3. Changes of soil water content in response to rainfall and irrigation water. (A) Response to rainfall. Soil water contents were recorded by sensor B2D3 in the non-irrigated experimental plot and sensor B467 in the experimental plot with soil water content controlled to more than $20 \%$ from October 11 to 12 in the 2019 growing season. Rainfall data were collected by the Meteorological Observation System located approximately $50 \mathrm{~m}$ from the experimental plots. (B) Response to irrigation water. Irrigation was performed for $10 \mathrm{~min}$ at 16:00 on May 29 in the 2017 growing season. Soil water contents in the irrigated experimental plots were recorded by sensors B467, AE75 and AE86. Arrows indicate the timing of irrigation. Dotted lines in graphs indicate $20 \%$ soil water content.

of soil water contents from April to October in the irrigated experimental plot were $29.9 \%$ as detected by B467; $25.2 \%$ by AE75 and $24.1 \%$ by AE86 in the 2017 growing season. The annual averages of soil water contents from April to October were $16.8 \pm 2.0 \%$, $18.4 \pm 1.9 \%$ and $18.5 \pm 1.9 \%$ (means \pm standard deviations for three sensors) in the non-irrigated experimental plot and $26.4 \pm 3.0 \%, 24.2 \pm 4.2 \%$ and $23.4 \pm 3.0 \%$ (means \pm standard deviations for three sensors) in the irrigated experimental plot for the 2017, 2018 and 2019 growing seasons, respectively.

In the experimental plots, soil field capacity (FC) that indicates the upper limit of water storage in soil was calculated according to Zotarelli et al. (2013). FC values calculated from B467, AE75 and AE86 in the 2017 growing season were $34.9 \pm 2.1 \%, 30.6 \pm 1.4 \%$ and $31.5 \pm 2.0 \%$, respectively.

Thus, real-time monitoring of soil water content by the wireless sensor networking system suggested that our experimental conditions and the use of an irrigation system realised constantly high soil water content $(>20 \%)$ during the grapevine growing season.

\section{Constantly high soil water content affects timing of véraison compared with non-irrigated experimental plot}

The timings of bud break, bloom, full bloom and harvest in grapevines of the experimental plot with soil water content controlled to more than $20 \%$ by irrigation were the same as those in the non-irrigated experimental plot in the three growing seasons (Table 2). The constantly high soil water content delayed the timing of véraison in the three growing seasons. Grapevines in the irrigated experimental plot showed extended timing of véraison by 10 days, 4 days and 1 day in the 2017, 2018 and 2019 growing seasons compared with those in the non-irrigated experimental plot, respectively. No morphological differences in shoot length, node 
A

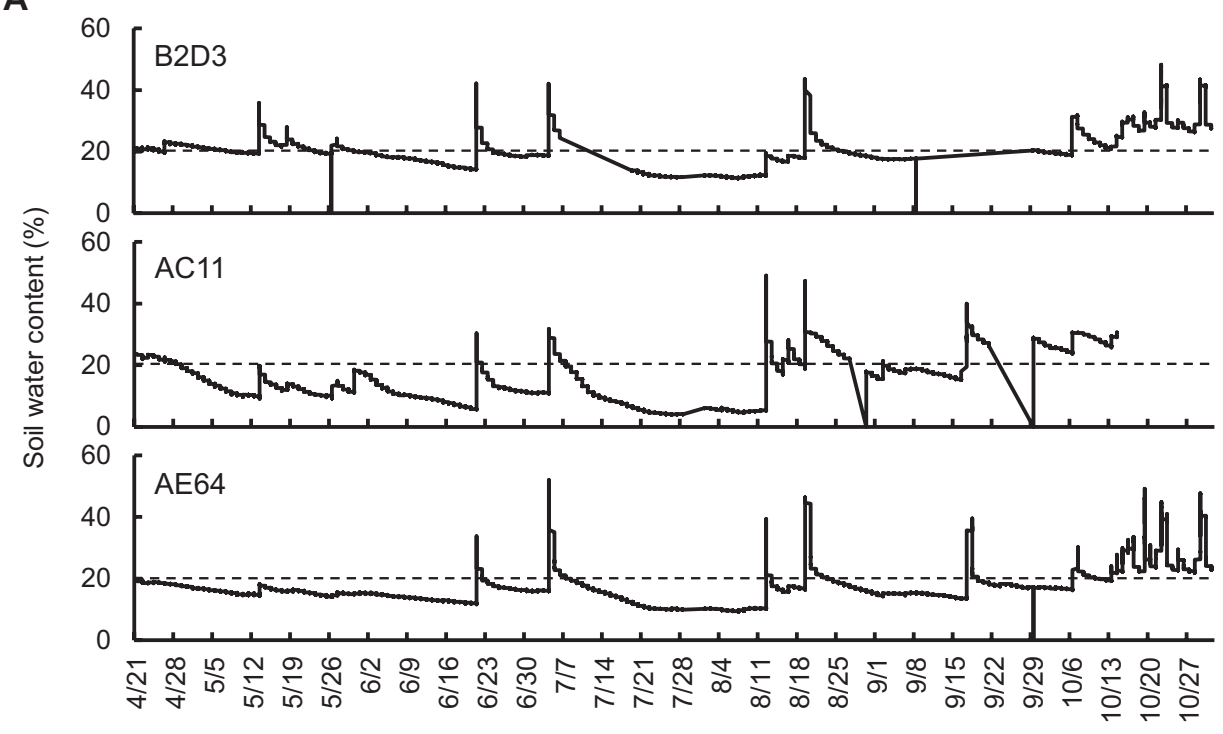

B

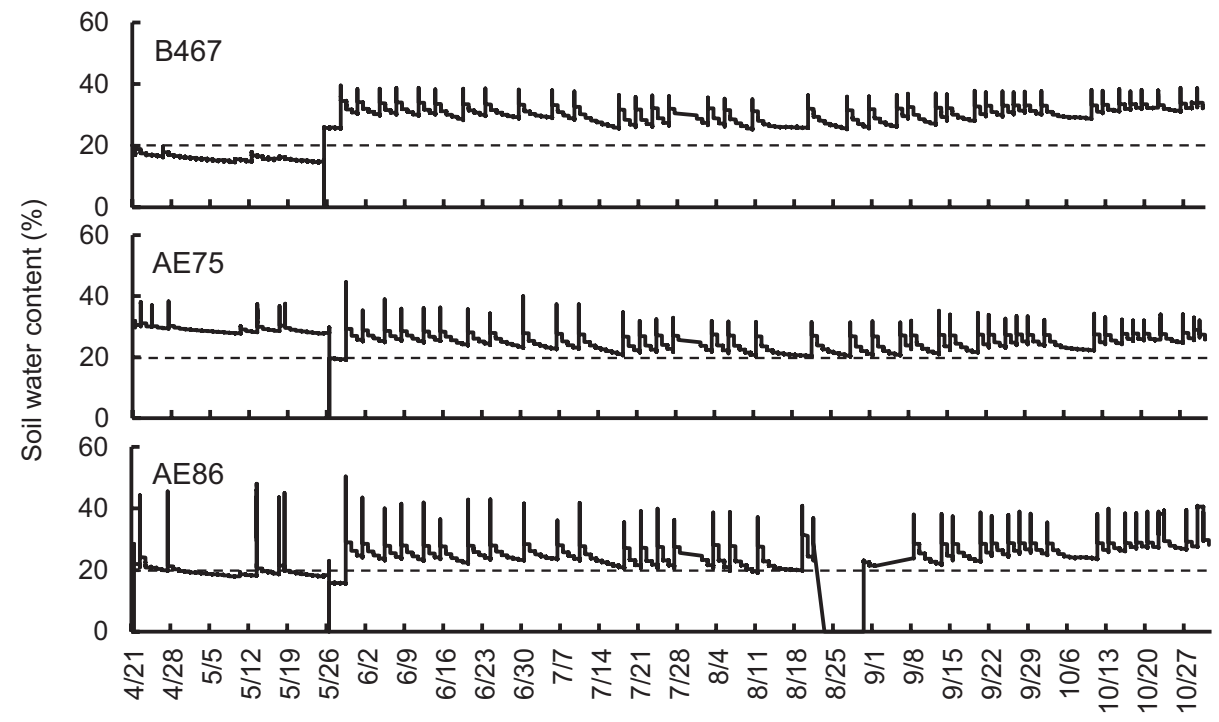

Figure 4. Representative profiles of soil water content in experimental plots. Soil water contents recorded by each sensor from April 21 to October 31 in the 2017 growing season are shown as representative profiles. (A) Non-irrigated experimental plot. (B) Irrigated experimental plot with soil water content controlled to more than $20 \%$. Dotted lines in graphs indicate $20 \%$ soil water content.

diameter and internode length during vegetative growth were observed between irrigated and non-irrigated grapevines (data not shown).

\section{Constantly high soil water content has no notable effects on leaf water potential}

Leaf water potential was measured before and after véraison to estimate water status in the experimental plots. No significant differences in leaf water potential were noted between irrigated and non-irrigated plots (Table 3) except the leaf water potential on 21 July 2018. Midday leaf water potential values ranged from -0.40 to -0.99 , suggesting no water stress in both experimental plots during the three growing seasons, in accordance with the report by van Leeuwen et al. (2007). The results suggested that the non-irrigated experimental plot had sufficient soil water content for grapevine growth and that soil in the irrigated experimental plot was supplied with an excess of water for grapevine growth.

\section{Effects of constantly high soil water content on berry quality at harvest}

Changes in transverse berry diameter, berry weight, soluble solids content and acid content were recorded in the 2017 growing season (Figure 5). The weight of 10 berries, soluble solids content and acid content in irrigated grapevines was occasionally lower than those 
Table 2. Effects of constantly high soil water content on timings of bud break, bloom, full bloom and véraison

\begin{tabular}{lllllll}
\hline Season & Treatment & Bud break & Bloom & Full bloom & Véraison & Harvest \\
\hline 2017 & Control & April 25 & June 2 & June 9 & August 9 & October 4 \\
& $>20 \%$ & April 25 & June 2 & June 9 & August 19 & October 4 \\
\hline 2018 & Control & April 16 & May 20 & May 28 & August 5 & October 1 \\
& $>20 \%$ & April 16 & May 20 & May 28 & August 9 & October 1 \\
\hline \multirow{2}{2}{2019} & Control & April 28 & May 28 & June 4 & August 7 & September 28 \\
& $>20 \%$ & April 28 & May 28 & June 4 & August 8 & September 28 \\
\hline
\end{tabular}

Control, non-irrigated grapevines; $>20 \%$, irrigated grapevines.

Table 3. Leaf water potential in grapevines

\begin{tabular}{llcc}
\hline Year & Date & \multicolumn{2}{c}{ Leaf water potential (MPa) } \\
\cline { 3 - 4 } & & Control & $>20 \%$ \\
\hline 2017 & August 2 & $-0.61 \pm 0.07$ & $-0.47 \pm 0.03$ \\
& August 11 & $-0.44 \pm 0.01$ & $-0.48 \pm 0.03$ \\
& August 23 & $-0.40 \pm 0.01$ & $-0.47 \pm 0.03$ \\
2018 & July 21 & $-0.99 \pm 0.08$ & $-0.68 \pm 0.04^{\mathrm{a}}$ \\
& July 23 & $-0.83 \pm 0.04$ & $-0.77 \pm 0.05$ \\
& July 25 & $-0.79 \pm 0.02$ & $-0.70 \pm 0.04$ \\
& July 30 & $-0.76 \pm 0.05$ & $-0.67 \pm 0.01$ \\
& August 13 & $-0.61 \pm 0.01$ & $-0.56 \pm 0.06$ \\
& August 15 & $-0.61 \pm 0.04$ & $-0.55 \pm 0.03$ \\
& August 18 & $-0.55 \pm 0.05$ & $-0.58 \pm 0.04$ \\
2019 & July 30 & $-0.61 \pm 0.04$ & $-0.61 \pm 0.01$ \\
& August 2 & $-0.62 \pm 0.02$ & $-0.61 \pm 0.02$ \\
& August 4 & $-0.63 \pm 0.05$ & $-0.63 \pm 0.01$ \\
& August 10 & $-0.77 \pm 0.03$ & $-0.71 \pm 0.04$ \\
August 12 & $-0.79 \pm 0.02$ & $-0.76 \pm 0.02$ \\
August 14 & $-0.71 \pm 0.02$ & $-0.72 \pm 0.02$ \\
\hline
\end{tabular}

Data are shown as means \pm standard errors of three leaves.

${ }^{a}$ Significant difference compared with control at $p<0.05$.

Control, non-irrigated grapevines; $>20 \%$, irrigated grapevines.

in non-irrigated grapevines. However, all berry qualities except acid content at harvest were comparable between irrigated and non-irrigated grapevines.

During the three growing seasons, there were no significant differences in bunch weight, bunch length, berry number per bunch, weight of 10 berries and soluble solids content at harvest between irrigated and non-irrigated grapevines (Table 4). Transverse berry diameters at harvest in irrigated grapevines were significantly smaller than those in non-irrigated grapevines in the 2018 and 2019 growing seasons. Although there was no significant difference, there was a certain tendency that anthocyanin contents in berry skins of irrigated grapevines decreased by treatment with constantly high soil water content compared with those of non-irrigated grapevines during the three growing seasons (Table 4). Constantly high soil water content decreased anthocyanin accumulation by approximately $80 \%$.

\section{DISCUSSION}

Wine production regions in Japan are located along the path of typhoons, and therefore those regions more or less have frequent rainfall and high humidity. In this study, the experimental plots were never subjected to water stress even in summer (Table 3). Under this environmental condition, the constantly high soil water content (more than 20\% during the grapevine growing season) delayed the growth of Cabernet Sauvignon berries in the 2017 growing season (Figure 4) and the timing of veraison compared with the non-irrigated experimental plot during the three growing seasons (Table 2). The growth retardation could be attributed to late véraison as a result of the constantly high soil water content. Since there was no difference in berry quality at harvest between irrigated and non-irrigated grapevines (Table 4), we postulated that late véraison resulting from the constantly high soil water content has a negligible impact on berry quality at harvest. There was a certain tendency that constantly high soil water content decreased anthocyanin contents in berry skins (Table 4). Since it is easy to imagine the possibility that pro-anthocyanidin content, which is influenced by anthocyanin biosynthesis (Bogs et al., 2005) and important for red winemaking, in berry skins and seeds may be affected by constantly high soil water content, future studies employing wine production using the berries of irrigated grapevines would reveal the negative effects of constantly high soil water content.

Increased precipitation due to global warming during the grapevine growing season (Frei et al., 1998) has been concerned in Japan as well. However, research of the effect of heavy rainfall-induced waterlogging on vegetative growth and berry quality of grapevines has not been carried out in Japan. Waterlogging generally creates a hypoxic soil condition (Christianson et al., 2010) and limits nutrient uptake and transport by plant roots (Boru et al., 2003). In grapevine, waterlogging reduced photosynthetic activity (Stevens and Prior, 1994) and vegetative growth (Kang et al., 2008). In contrast, the present study demonstrated that a constantly high soil water 

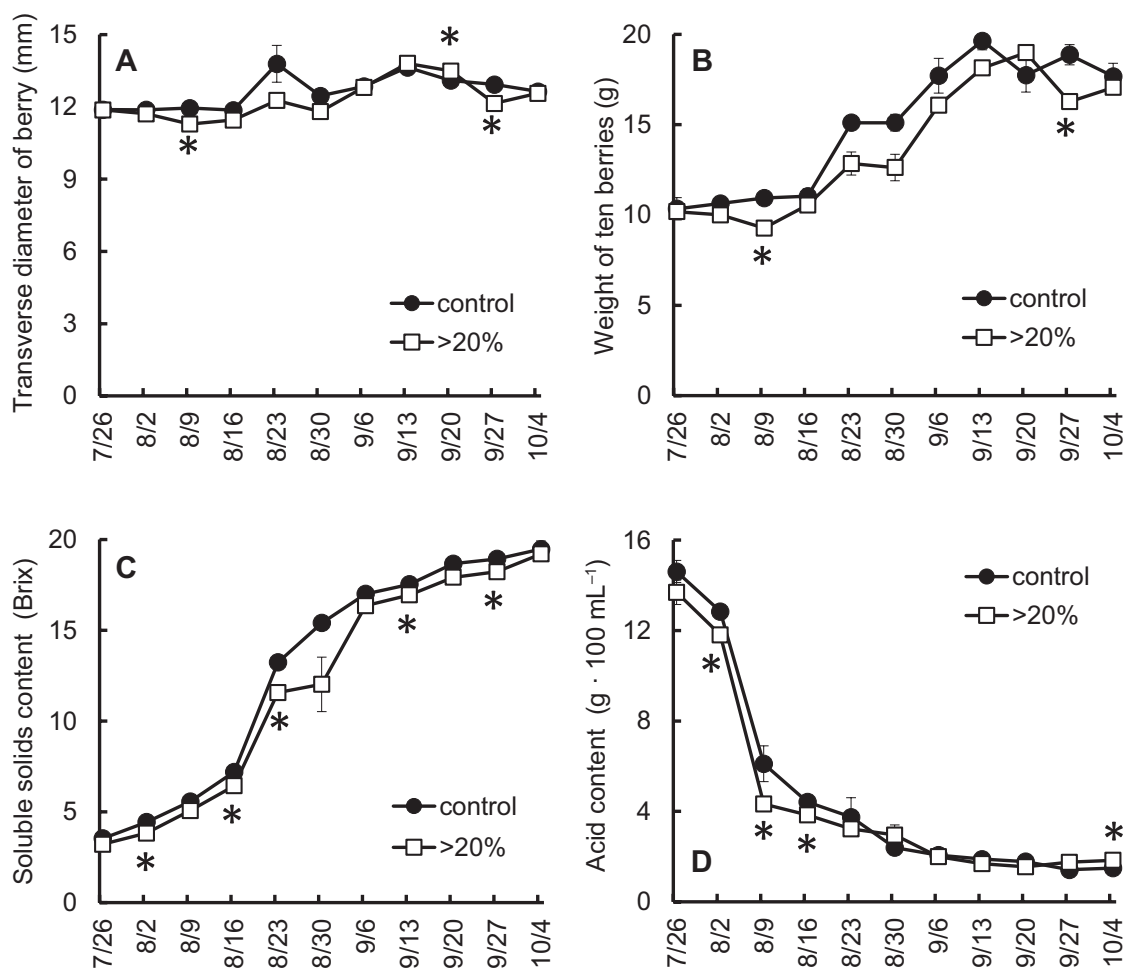

Figure 5. Effects of constantly high soil water content on berry characteristics. Berry characteristics were measured from July 26 to October 4 in the 2017 growing season. (A) Transverse diameter of berry. (B) Weight of 10 berries. (C) Soluble solids content (Brix). (D) Acid content. Control (•), non-irrigated grapevines; $>20 \%$ ( $\square$ ), irrigated grapevines. Data are means \pm standard errors determined from three bunches collected on each sampling day. ${ }^{*} p<0.05$ compared with control.

content had no notable effects on grapevine vegetative growth except veraison, compared with non-irrigated grapevines (Table 2). Low soil temperature caused by waterlogged soil condition restricted grapevine growth (Bennie and Hensley, 2004). In the present study, there was no difference in soil temperature between non-irrigated and irrigated experimental plots due to sheet treatment to maintain a constantly high soil water content. In addition, we grafted Cabernet Sauvignon to 101-14 Millardet et de Grasset rootstock that shows high tolerance to waterlogging stress ( $\mathrm{Li}$ et al., 2013). Viticultural practices to avoid waterlogging damage, such as ridging (Myburgh and Moolman, 1991), have been examined. From our results, we postulated that the selection of rootstock that confers tolerance to waterlogging stress for scion cultivars and/ or viticultural practices to prevent soil temperature decrease by frequent rainfall may prevent waterlogging damage caused by the increase in soil water content. Further studies evaluating scion cultivar-rootstock interaction under high soil water content are necessary to suppress waterlogging stress.

Water status of vineyard soil is a key environmental factor in the vegetative growth and berry quality of grapevines (van Leeuwen et al., 2009). In the present study, soil moisture sensors were buried $20 \mathrm{~cm}$ underground (Figure 1). More than half of the roots are concentrated in the area 25 and $50 \mathrm{~cm}$ underground (Champagnol, 1984). However, variations of soil water content at deeper levels are not negligible (Pellegrino etal., 2005). Further studies to understand the effects of high soil water content on vegetative growth and berry quality of grapevines using multiple sensors installed at different depths underground may contribute to improving countermeasures for waterlogging damage caused by frequent rainfall in Japan.

\section{CONCLUSIONS}

Since high soil water content may decrease anthocyanin contents in berry skins, monitoring of water status in vineyard soil is one of the important management tools in viticulture. An original wireless sensor networking system for real-time monitoring of soil water content was developed in the present study. The installation of wireless sensor networking systems in vineyards is becoming common for monitoring water status in vineyards. The introduction of IoT technology including remote and real-time monitoring of environmental conditions in vineyards is expected to contribute to precision farming and improving practical approaches to vineyard management. The findings in this study are expected to contribute to grape cultivation managements in Japan and/or much rainfall area. 


\section{ACKNOWLEDGEMENT}

This study was grant supported by a Grant-in-Aid for Scientific Research (C) No. 17K07639 from the Ministry of Education, Culture, Sports, Science and Technology of Japan to S. Suzuki.

\section{AUTHOR CONTRIBUTIONS}

Y.K., H.I., R.S. and S.S. developed the concept and designed the experiment; Y.K. T.Y. and R.S. collected data and performed analyses and Y.K., H.K., M.K. and S.S. analysed the data and wrote the paper.

\section{CONFLICT OF INTEREST}

The authors declare no conflicts of interest.

\section{REFERENCES}

Bennie, A. T. P., And Hensley, M. (2004). Advances in soil physics and soil water management research in South Africa, 1979-2003. South African Journal of Plant Soil, 21, 268-277.

Bogs, J., Downey, M. O., Harvey, J. S., Ashton, A. R., Tanner, G. J., And Robinson, S. P. (2005). Proanthocyanidin synthesis and expression of genes encoding leucoanthocyanidin reductase and anthocyanidin reductase in developing grape berries and grapevine leaves. Plant Physiology, 139, 652-663.

Boru, G., Vantoai, T., Alves, J., Hua, D., And Knee, M. (2003). Responses of soybean to oxygen deficiency and elevated root-zone carbon dioxide concentration. Annals of Botany, 91, 447-453.

Bravdo, B., Hepner, Y., Loinger, C., Cohen, S., and TABACMAN, H. (1985). Effect of irrigation and crop level on growth, yield and wine quality of Cabernet Sauvignon. American Journal of Enology and Viticulture, 36, 132-139.

Champagnol, F. (Ed.) (1984). Eléments de physiologie végétale et de viticulture générale (p. 351). France: Saint Gely du Fesc.

Christianson, J. A., Llewellyn, D. J., Dennis, E. S., AND Wilson, I. W. (2010). Global gene expression responses to waterlogging in roots and leaves of cotton (Gossypium hirsutum L.). Plant and Cell Physiology, 51, 21-37.

Fraga, H., García De Cortázar Atauri, I., AND Santos, J. A. (2018). Viticultural irrigation demands under climate change scenarios in Portugal. Agricultural Water Management, 196, 66-74.

Frei, C., Schär, C., Lüthi, D., And Davies. H. C. (1998). Heavy precipitation processes in a warmer climate. Geophysical Research Letters, 25, 1431-1434.

Gao, Z., Zhu, Y., Liu, C., Qian, H., CaO, W., And Ni, J. (2018). Design and test of a soil profile moisture sensor based on sensitive soil layers. Sensors, 18, 1648 . 
GonzÁlez-Teruel, J. D., Torres-SÁnchez, R., Blaya-Ros, P. J., Toledo-Moreo, A. B., Jiménez-Buendía, M., and Soto-Valles, F. (2019). Design and calibration of a low-cost SDI-12 soil moisture sensor. Sensors, 19, 491.

Hatsuzuka, D., and Sato, T. (2019). Future changes in monthly extreme precipitation in Japan using largeensemble regional climate simulations. Journal of Hydrometeorology, 20, 563-574.

Jones, G. V., White, M. A., Cooper, O. R., And Storchmann, K. (2005). Climate change and global wine quality. Climatic Change, 73, 319-343.

Kang, S. B., Lee, I. B., JAng, H. I., PArk, J. M., And Moon, D. K. (2008). Effect of long term waterlogging on the growth and nutrient contents of 'Campbell Early' and 'Kyoho' grapevine cultivars. Korean Journal of Environmental Agriculture, 27, 178-184.

Kobayashi, Y., Yamamoto, T., Naito, H., Shindate, Y., AND Suzuki, S. (2020). High cordon training system reduces labor hours and load compared with conventional cordon training system. Catalyst: Discovery into Practice, 4(1), 1-9.

LI, Y., Fu, Y. D., MA, Y. C., Du, Y. P., AND ZhAi, H. (2013). Effects of waterlogging on characteristics of growth and photosynthesis in different grape rootstocks. Scientia Agricultura Sinica, 46, 995-1004.

Myburgh, P. A., And Moolman, J. H. (1991). The effect of ridging on the soil water status of a waterlogged vineyard soil. South African Journal of Plant Soil, 8, 184-188.

Nooriman, W. M., Abdullah, A. H., Rahim, N. A., And Kamarudin, K. (2018). Development of wireless sensor network for Harumanis Mango orchard's temperature, humidity and soil moisture monitoring. Paper presented at the IEEE Symposium on Computer Applications \& Industrial Electronics, Penang, Malaysia, 263-268.

Pellegrino, A., Lebon, E., Voltz, M., and Wery, J. (2005). Relationships between plant and soil water status in vine (Vitis vinifera L.). Plant Soil, 266, 129-142.

Schultz, H. R. (2003). Differences in hydraulic architecture account for near isohydric and anisohydric behaviour of two field-grown Vitis vinifera L. cultivars during drought. Plant, Cell \& Environment, 26, 1393-1405.

Spachos, P., AND Gregori, S. (2019). Integration of wireless sensor networks and smart UAVs for precision viticulture. IEEE Internet Computing, 23, $8-16$.

Stevens, R. M., And Prior, L. D. (1994). The effect of transient waterlogging on the growth, leaf gas exchange, and mineral composition of potted Sultana grapevines. American Journal of Enology and Viticulture, 45, 285-290.

Tsuguti, H., Seino, N., Kawase, H., Imada, Y., Nakaegawa, T., AND TAKAYABU, I. (2019). Meteorological overview and mesoscale characteristics of the heavy rain event of July 2018 in Japan. Landslides, 16, 363-371.

VanLeeuwen, C., Trégoat, O., Choné, O., Gaudillère, J.P., and Pernet, D. (2007). Different environmental conditions, different results: the role of controlled environmental stress on grape quality and the way to monitor it. Paper presented at the 13th Australian Wine Industry Technical Conference, Adelaide, Australia, 39-46.

Van Leeuwen, C., Trégoat, O., Choné, X., Bois, B., Pernet, D., And Gaudillère, J. P. (2009). Vine water status is a key factor in grape ripening and vintage quality for red Bordeaux wine. How can it be assessed for vineyard management purposes? OENO One, 43, 121-134.

Yokoyama, C., Takayabu, Y. N., Arakawa, O., and Ose, Y. (2019). A study on future projections of precipitation characteristics around Japan in early summer combining GPM DPR observation and CMIP5 large-scale environments. Journal of Climate, 32, 5251-5274.

Zotarelli, L., Dukes, M. D., And Morgan, K. T. (2013). Interpretation of soil moisture content to determine soil field capacity and avoid over-irrigating sandy soils using soil moisture sensors. Agricultural and Biological Engineering Department, Florida Cooperative Extension Service, Institute of Food and Agricultural Sciences, University of Florida, 1-4.

Received April 9, 2020; accepted July 13, 2020 